\section{REDIMAT}

Journal of Research in Mathematics Education
Hipatia Press

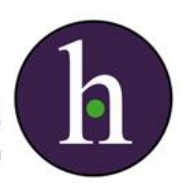

Instructions for authors, subscriptions and further details:

http://redimat.hipatiapress.com

\title{
Contextualizing Mathematics Related Affect: Significance of Students' Individual and Social Level Affect in Finland and Chile
}

Laura Tuohilampi ${ }^{1}$

1) University of Helsinki, Finland

Date of publication: February $24^{\text {th }}, 2016$

Edition period: February 2016-June 2016

To cite this article: Tuohilampi, L. (2016). Contextualizing Mathematics related affect: Significance of students' individual and social level affect in Finland and Chile. REDIMAT, 5(1), 7-27. doi: 10.4471/redimat.2016.1823

To link this article: http://dx.doi.org/10.4471/redimat.2016.1823

PLEASE SCROLL DOWN FOR ARTICLE

The terms and conditions of use are related to the Open Journal System and to Creative Commons Attribution License (CC-BY). 


\section{Contextualizing Mathematics Related Affect: Significance of Students' Individual and Social Level Affect in Finland and Chile}

Laura Tuohilampi

University of Helsinki

(Received: 9 November 2015; Accepted: 7 February 2016; Published: 24 February 2015)

\section{Abstract}

Mathematics related affect turn from positive to negative during comprehensive school years worldwide. There is a clear need to find solutions to the problem. However, some gaps and problems appear in the methodologies and the common approaches used in the field. This article discusses five studies addressing affective development, challenges some of the methods and approaches to measure the development and presents some possibilities to make a change in such a development. The frameworks of the studies, as well as their methods, data and results are briefly presented. Based on the studies, we confirmed several dilemmas concerning affect research and the significance of mathematics-related affect across two cultures. We identified the cultural meaning of different affective levels, and elaborated the social comparison the students live through their school years. As a conclusion, we formulated several suggestions to take into account in future studies. What counts especially is the need to be culturally sensitive in the affect domain.

Keywords: Mathematics-related affect, cross-cultural comparison, methodology, development, significance 


\section{Contextualizando el Afecto Hacia las Matemáticas: Significatividad del Afecto Individual y Social de los Estudiantes en Finlandia y Chile}

Laura Tuohilampi

University of Helsinki

(Recibido: 9 Noviembre 2015; Aceptado: 7 Febrero 2016; Publicado: 24 Febrero 2016)

\section{Resumen}

En todo el mundo el afecto hacia las matemáticas se torna de positivo a negativo durante los primeros años escolares. Hay una necesidad clara de encontrar soluciones a este problema. Sin embargo, existen algunos vacíos y problemas en las metodologías y en los enfoques comunes usados en este campo. Este artículo discute cinco estudios dirigidos al desarrollo afectivo, analizando los métodos y enfoques para medir el desarrollo y presentando algunas posibilidades para realizar cambios en este desarrollo. A partir de estos estudios, hemos confirmado algunos dilemas a cerca de la investigación en afecto y la significatividad del afecto relacionado con las matemáticas en dos culturas. Hemos identificado significados culturales en diferentes niveles afectivos, y hemos elaborado una comparación social de la vida de los estudiantes en sus años académicos. Como conclusión, hemos formulado algunas sugerencias a tener en cuenta en futuros estudios. Lo que cuenta es la necesidad de ser culturalmente sensible en el ámbito del afecto.

Palabras clave: Afecto relacionado con las matemáticas, comparación a través de las culturas, metodología, desarrollo, significatividad 
$\mathbf{R}$

esearch shows that pupils feel good about their skills and enjoy what they are working with when they start going to school. However, the becomes less positive. This is said to be normative development (Harter, 1999), and happens primarily in order to contribute to a realistic self-concept (ibid.). Unfortunately, the development goes beyond what is realistic with the case of mathematics. During school years, mathematics related affect turn unnecessary negative and even harmful for learning. In large scale studies by Lee (2009) and by Sjøberg and Schreiner (2010) the international development has been examined, finding out that students all over the world most likely end up carrying negative affect towards mathematics. In Finland the same problem exists despite the internationally high performance level. In a recent study by Hirvonen (2012) Finnish students who were finishing comprehensive school expressed fairly low self-competence in mathematics, and especially students' emotions towards mathematics were negative across the performance level.

There has been extensive research about the phenomenon worldwide. We have conducted five recent studies around the theme, and in this article the main results from the five studies will be introduced. First, we discuss the development of the affect and its factors (research task 1). After that we will problematize the common methods to measure affect in different cultures (research task 2). Then we will use students' drawings to analyze what they expressed about their mathematics classes (research task 3), and finally consider the development of both individual and social affect of the students (research task 4). The five studies contribute to our understanding about mathematics related affective levels, the affective level's cultural significance and the problems that can particularly cause the problem of deteriorating mathematics related affect.

\section{Theoretical Approaches to Mathematics Related Affect}

Over the years the studies in mathematics related affect domain almost systematically have focused on measuring students' individual level affect. In Chamberlin's (2010) study, he provides an overview of the instruments created to assess affect in mathematics. Many of the instruments are based 
on the Fennema-Sherman scale (Fennema \& Sherman, 1976), developed back in 70's when researchers were specifically interested in mathematics anxiety. In 1997, Ma \& Kishor published a meta-analysis of studies that have examined the relationship between attitude towards mathematics and achievement in mathematics. In that meta-analysis, they found out that the effect size between the two concepts was relatively small, and that mathematics related affect is not as strongly connected with performance as perceived. Since that, the domain has been developed to several directions. In this article, especially the following directions are of interest: towards more social (e.g. Yackel \& Cobb, 1996), towards more emotional (Pekrun, 2006), towards more culturally sensitive (Clarke, 2013) and towards more theoretically accurate (Hannula, 2011; 2012).

\section{Concepts}

In a profound work of McLeod (e.g. 1992), the theoretical approaches regarding mathematics related affect were widely discussed. As a conclusion, McLeod structured the area into emotions, beliefs, and attitudes. The idea was that the experiences the students face when being involved with mathematics learning cause emotional (physiological) reactions. Over time, these reactions develop into more stable attitude, namely presumptions or expectations about coming mathematics-related experiences. The term attitudes, however, has rarely been made explicit in studies (Di Martino \& Zan, 2015), and it has been used to refer to varying concepts.

In 2011, Hannula reconstructed the theoretical model of mathematics related affect suggesting affect to construct of cognitive component (beliefs, conceptions), emotional component and motivational component, all the three components having manifestations in constancy dimension and contextual dimension as well. The cognitive component includes much of what in earlier mathematics related affect research has been discussed under the concept of beliefs (see e.g. McLeod, 1992; Pehkonen, 1994). The emotional component is defined by Hannula (2011) as "typical emotional reactions to typical situations in the mathematics classroom" (p. 45), referring to trait aspect: the reactions that typically arrive. The motivational component refers to conative elements that in general reflect personal preferences and choices. Several theoretical approaches have been used in 


\section{$8 \quad$ Laura Tuohilampi-Affect and Significance}

motivation research, but in this article we use the model of goal orientations by Midgley and others $(1998 ; 2000)$. Regarding goal orientations, there is a distinction of mastery goal orientation, wherein the student wants to learn because of inner, non-profit reasons, and of performance goal orientation, wherein the student wants to learn because of outside rewards (because of a degree, because of social acceptance etc.).

The trait and state aspects in Hannula's model refer to affective components' constancy. The constancy is seen in rapidly changing contextual situations: for example in problem solving the changing emotions and beliefs influence the critical choices that determine whether a problem will be solved or not. This would be the affective state. Affective trait, on the other hand, is a more stable pattern affecting how an individual feels and thinks in different contexts and about different situations.

The third dimension in Hannula's model refers to context. Psychological and physiological seem to refer to individual level phenomena, while social to interindividual level phenomena. In addition to the three dimensions, there is one more element established in affect research: the intensity of the affective elements, as well as the degree of stability in response. This has been discussed by Evans (2006) and McLeod (1992), but it is not explicitly present in Hannula's model. In the model, we could think the cognitive component to be the most stable and least intense, as beliefs are reported to be fairly resilient. Emotional component could be considered as the most intensive. However, emotions can be very constant and robust, but not necessarily intensive (like boredom). On the other hand, spontaneous emotional reactions can be very intensive, but less constant (like anger).

\section{Contextual Levels}

Historically, the individual experiences may have been interpreted with the help of contextual variables, such as family expectations, parents' educational levels, or school culture. Bronfenbrenner (1993) approaches context dividing it to four levels: (1) the micro level including an individual's interaction with other individuals, (2) the meso level including groups of microsystems interacting with each other (e.g. classes interacting with teachers), (3) the exo level including linkages and processes between social institutions (e.g. the school system, government, family structures), and (4) the macro level including the interaction of all the three lower 
levels. The contextual levels were present and visualized in the summary of affective working group of the $5^{\text {th }}$ Congress of European Research of Mathematics Education (CERME) (Hannula, Op 't Eynde, Schlöglmann \& Wedege, 2007, p. 41). In that summary, the structure of the affective domain included three contextual levels (Figure 1). The three levels resemble Bronfenbrenner's levels: Student / teacher the micro level, Classroom context the meso level, and socio-historical context the exo and macro levels.

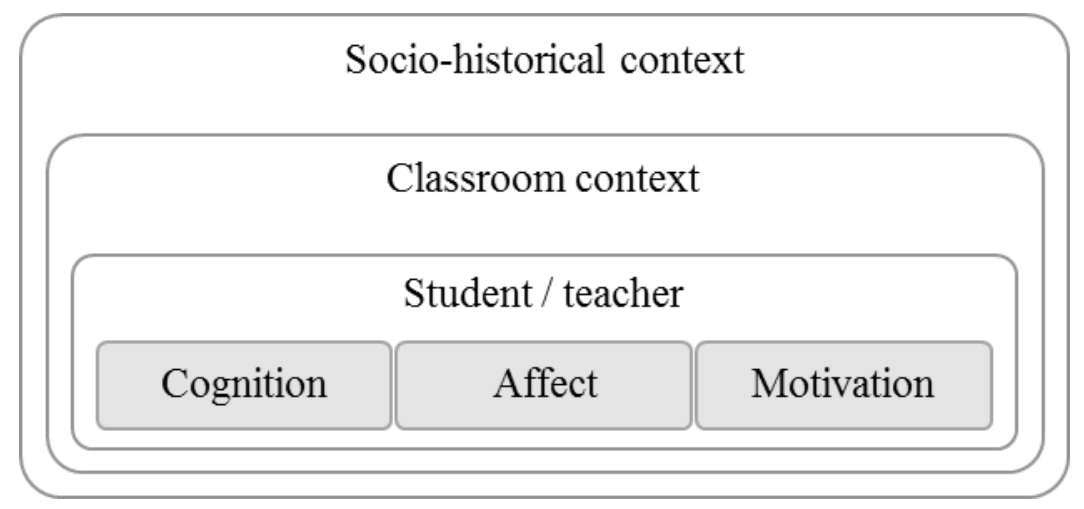

Figure 1. The contextual structure of affect domain

\section{Social Turn}

A decade ago Lerman (2000) discussed the "social turn" in mathematics education. Since that, research on the higher levels of context has been growing systematically. In Thapa, Cohen, Guffey and Higgins-D' Alessandro (2013), the 206 reviewed studies were addressing five dimensions of school climate: safety, relationships, teaching and learning, institutional environment and school improvement process. Evans, Harvey, Bucley and Yan (2009) define social atmosphere of the classrooms through three complementing components: 1) academic, referring to pedagogical and curricular elements of the learning environment, 2) management, referring to discipline styles for maintaining order, and 3) emotional, the affective interactions within the classroom. 


\section{Laura Tuohilampi-Affect and Significance}

Hannula (2012) discusses the mathematics education research about social systems indicating that the characteristics of learning communities are powerful predictors for students' academic success. He recognizes that classroom goal structure has been researched within the achievement goal theory, and reports that mastery goal structures have a positive effect on interindividual relations, whereas performance goal structure have negative or non-significant effects on different types of interindividual relations. Hannula (ibid.) states that studies on classroom affect and motivation often emphasize the teacher role in the establishment of classroom discourse and motivational orientation, paying less attention to the students' role in the establishment of the classroom climate. However, students' participation was included in a study of Turner, Midgley, Meyer, Gheen, Anderman, Kang and Patrick (2002), who examined how classroom goal structure and discourse affected students' use of avoidance strategies. They found out that the avoidance strategies appeared significantly less in classrooms perceived as emphasizing learning, understanding, effort, and enjoyment. Also Reyes, Brackett, Rivers, White, and Salovey (2012) studied the emotional climate of the classrooms, finding direct and indirect links with academic achievement. Being impacted by the students, the teacher, or both, the affective learning environment seems like a significant element in learning and wellbeing. In sum, Thapa et al (2013) report that school climate has shown to affect middle school students' self-esteem, mitigate the negative effects of self-criticism, impact a wide range of emotional and mental health outcomes, and have a positive correlation with self-concept.

\section{Normative Affective Development}

According to developmental psychology, self-construction is influenced by social and contextual factors. The social surrounding plays a role in dictating what experiences are most salient and to be encoded (Harter, 1999). During the childhood children start to make self-evaluations by comparing oneself with others. At the beginning children feel very positive about her/himself, having almost omnipotent view of her/his potential. Little by little the self-construction becomes more accurate, allowing both positive and negative evaluations.

The developmental view presented by Harter (1999) is in line with Op 't Eynde, de Corte, and Verschaffel (2002), who argue that affect become 
from what is "first told". This means that if there is nothing that contradicts with given information (true or false), children tend to take it as true. Only when a contradiction appears, children have a reason to evaluate former affect, as well as given information in the light of the former affect. Interacting with peers children start to evaluate their skills and appearance according to the reactions of others. This developmental phase places itself into early school years: from Table 1 you can find Harter's (1999, p.36) presentation about the normative developmental steps in the childhood.

Table 1

Harter's (1999) developmental stages of self-construction

\begin{tabular}{|c|c|c|}
\hline Age Period & Valence /Accuracy & Sensitivity to Others \\
\hline $\begin{array}{l}\text { Very early childhood } \\
\text { (3-4 years old) }\end{array}$ & $\begin{array}{l}\text { Unrealistically positive; } \\
\text { inability to distinguish } \\
\text { real from ideal selves }\end{array}$ & $\begin{array}{l}\text { Anticipation of adult } \\
\text { reactions; rudimentary } \\
\text { appreciation of whether } \\
\text { one is meeting others' } \\
\text { external standards }\end{array}$ \\
\hline $\begin{array}{l}\text { Early to middle } \\
\text { childhood }(5-7 \text { years } \\
\text { old) }\end{array}$ & $\begin{array}{l}\text { Typically positive; } \\
\text { inaccuracies persist }\end{array}$ & $\begin{array}{l}\text { Recognition that others } \\
\text { are evaluating the self; } \\
\text { initial introjection of } \\
\text { others' opinions: others' } \\
\text { standards becoming self- } \\
\text { guides in regulation of } \\
\text { behaviour }\end{array}$ \\
\hline $\begin{array}{l}\text { Middle to late childhood } \\
\text { ( } 8-11 \text { years old) }\end{array}$ & $\begin{array}{l}\text { Both positive and } \\
\text { negative evaluations; } \\
\text { greater accuracy }\end{array}$ & $\begin{array}{l}\text { Internalization of others' } \\
\text { opinions and standards, } \\
\text { which come to function } \\
\text { as self-guides }\end{array}$ \\
\hline
\end{tabular}

\section{Cross-Cultural Comparison}

Some instruments, such as Fennema-Sherman scale have been particularly influential in the mathematics related affect domain. Even the large-scale comparative studies, like Programme for International Student Assessment (PISA) by the Organization for Economic Cooperation and Development 


\section{Laura Tuohilampi-Affect and Significance}

(OECD) and TIMSS surveys use scale that is Fennema-Sherman originated. Like Fennema-Sherman scale, which is US-originated, also other dominant instruments have been developed by Western researchers (Chamberlin, 2010). To use such an instrument to other cultures than Western is an "imposed-etic approach" wherein the researchers impose their own perspective to the studied culture (Berry, 1989). According to Berry (ibid.), there are three approaches to cultural comparisons: imposed-etic approach, emic approach and derived-etic approach. Having an insider's view to examined topic takes the imposed-etic approach to the next level, i.e. to the emic level. The most desired stage according to Berry (ibid.) is the third stage, the derived-etic stage, which includes deducing features that are common to both (or all) cultures to compare and that have been derived from emic research in each culture.

Clarke (2015) points out that cultural differences may invalidate the use of imposed-etic approach in the field of mathematics education research. In his earlier study, Clarke (2013) discussed the challenges of cross-cultural comparisons, suggesting a validity-comparability compromise. Clarke introduced seven dilemmas: 1) Cultural specificity of cross-cultural codes, 2) Inclusive vs. distinctive, 3) Evaluative criteria, 4) Form vs. function, 5) Linguistic preclusion, 6) Omission, and 7) Disconnection. We identified four out of seven dilemmas to connect with imposed-etic approach. First, the dilemma of inclusiveness vs. distinctiveness regards a presumption that all cultures share similar and universal categories concerning the subjects under investigation and that the content of the categories are easily recognizable and similarly interpreted. Second, the dilemma of evaluation criteria points out that different cultures value things differently. This leads to evaluations that emphasize things differently. In comparative measurements, non-fulfillment of standards is typically interpreted as a sign of failure, but this dilemma points out that "the failure" can be just a sign of those things not have been valued that much (instead of something else that was not addressed in comparison). Third, Clarke's dilemma of linguistic preclusion reminds that by using the imposed-etic approach, one might end up comparing variously interpreted or non-existent terminology. Also Andrews \& Diego-Mantecón (2014) have recently criticized such a presumption about universal congruence between languages and conceptions. Finally, Clarke presented the dilemma of omission, that is, 
when a researcher is unable to include all that is essential when making attempts to research another culture.

\section{Finland and Chile}

In affect research, Finland is perennially placed to fit into the European and North American group of countries. Math anxiety and math self-concept seem to have similar roles in Finland as they have inside this Western division, in contrast to for example the Confucian Heritage Culture countries (Lee, 2009; Wong, 2008). When it comes to Latin America, Chile, despite in many ways fitting into the mold of a modern country, is reported to have an achievement level very different from most Western (including North European) countries. Here, Finland is perceived as representing individual Western culture and Chile as collectivist Latin culture (see also Hofstede \& Hofstede, 2005).

\section{The Centrality / Significance of Affect}

Back in 70's, Green (1971) argued that beliefs build up discrete, separate clusters. This makes possible to simultaneously have beliefs that are in contradiction, allowing some beliefs to become more central than others. McLeod (1992) discussed the same idea, suggesting that the most central beliefs will be the ones the belief holder has complete consensus about. Those being imposed by authorities become the least central. Chapman (2002) has confirmed the centrality of affect structures empirically. Based on her study, a change in the less central ones do not necessarily have any impact on the overall affect structure, as the most central components overrule. For example, if a student deeply perceives mathematics as boring, this perception may still remain even if the same student starts to see mathematics more important. The importance and the boring nature of the subject might be contradictory, but if the boredom is more central to the student, this dominates student's view of the subject (which is likely, as feelings are typically personally generated, and the idea of subject's importance imported by authorities).

Culture determines to some extent how much individuals value norms that are brought outside. For example, in the individual cultures the personal experiences may become the most central. On the contrary, in the 
collectivist cultures the social experiences may become such. This cultural variation is discussed by Markus and Kitayama (1991), who argued that if the culture is individual, then individual level phenomena become very significant, structured and well identifiable, while in collective cultures the interindividual phenomena become more significant, more structured and more easily identified.

\section{Results of the Five Studies}

\section{Research Task 1}

The data consisted of 3,502 Finnish students (1,702 girls, 1,800 boys) who were followed throughout comprehensive school years regarding mathematics achievement and mathematics related affect. The measurements were done at the beginning of third, sixth, and at the end of ninth grade (years 2005, 2008, and 2012, respectively).

As a result, we saw that in the first measurement the pupils' individual level mathematics-related affect was very positive. The mean for overall affect score was $71 \%$. During the following years the affect turned negative. The overall affect score decreased from $71 \%$ to $60 \%$ by the second measurement, and to $52 \%$ by the last measurement. The decrease did not happen in a similar vein regarding both of the affective components. When examining the dimensions separately, we found out that the decrease began stronger with respect to Enjoyment. In first measurement, this component was at a high level $(72 \%)$, but by the second measurement it had decreased to $54 \%$. The decrease continued after that, but less dramatically: at the last measurement the degree of that component was 47 $\%$. Regarding Self-efficacy, the decrease was very reasonable between the first and the second measurement (from $68 \%$ to $66 \%$ ) despite the decrease of the Enjoyment. Instead, by the last measurement the Self-efficacy decreased very clearly, becoming $57 \%$ of the maximum score.

With respect to the different genders, the development of affect was similar, but the decrease was more dramatic regarding girls. At the first measurement, the mean for girls was $68 \%$, whereas the mean for boys was $72 \%$. At the second measurement, the mean for girls was $57 \%$, while for boys it was $64 \%$, and at the third measurement the mean for girls was 50 
$\%$, whereas the mean for boys was $54 \%$. In all three measurements the difference between genders was statistically significant.

\section{Research Task 2}

The data were collected within an intervention project aiming to develop mathematics learning in Finland and Chile. In Finland, the number of participants was 466 and in Chile 901, which makes the total number of participants 1,367 . The data were collected at the beginning of the 2010 2011 academic year. The questionnaire was administered to $3^{\text {rd }}$ graders. On the whole, the data were considered to be representative of urban pupils in both countries.

The intervention was built around monthly activities with mathematical problems, aiming the classes to become more active and the teachers to more vary their working methods. The mathematical problems were in most cases open ended. The teachers were allowed and instructed to execute the problem solving sessions according to their own preferences. Most commonly, the teachers used collective activities wherein pupils were allowed to discuss the problems, to move, and to work collaboratively. The lessons were filmed, and the teachers could use the videos to support their process in developing the activities during the intervention.

We used a shortened and simplified version of the instrument used by Hannula \& Laakso (2011) to measure 4th grade Finnish pupils, which made the method as imposed-etic for Chilean data. We conducted exploratory factor analyses to find out the structures of pupils' mathematics-related affect. The found factors' precision with the theoretical dimensions represented in the questionnaire was evaluated by examining the factors congruence with the theoretical dimensions. When comparing the structures, we noticed that the extent of the congruence between the explanatorily factors and the theory based factors differed between the countries. Also, the more compressed the structure, the less it was congruent with theory: this was seen with respect to both countries' structures. All in all, there was no obvious universality between the structures. 


\section{Research Task 3}

The intervention data was used to ask this question. It was aimed to find out what is the degree of the individual level and social level of mathematics related affect in Finland and Chile and what is the congruence between these levels. The individual level data was the same as in research task 2, collected through a questionnaire. The social level data was collected through drawings: we asked the examinees to draw their mathematics class. The pupils were allowed to draw only one moment in their drawings, but they were free to choose what moment to draw and what to emphasize.

According to the questionnaire, the pupils' individual level of affect regarding mathematics was mainly positive in both countries. Almost no pupils were having negative affect in either of the countries, but in Chile there were more pupils in the middle category than there were in Finland. There was a statistically significant difference between the countries. Regarding the social level, the pupils seemed to be more negative in Finland. There was a statistically significant difference between the countries. The individual level distributions appeared independent on the content of the drawing. Thus, the two levels of affect were statistically independent regarding both countries.

In the thematic analysis of the drawings, we found four categories present in both countries: Easy and difficult, Disturbance, Boredom or sleepiness and Positive and negative emotions. The countries differed a bit regarding the categories and there were more categories in Chile. Furthermore, the students were not as uniform across the classes in Chile as they were in Finland. In Chile, the interindividual level varied more and the pupils expressed lots of things with reference to their surroundings, even complicated ones.

\section{Research Task 4}

For a longitudinal analysis of the intervention, the data used for tasks 2 and 3 were completed with post test data. Only Finnish dataset was discussed. The number of pupils that participated either in the pre-test, the post-test or both tests was 320. The post-test data were collected at the end of the academic year 2013-2014 during April-May. In the pre-test, there were 25 classes involved; 10 out of these classes were intervention groups, while the 
rest of them were control groups. In the post-test, 6 control groups were not reached and 2 intervention groups left the project.

We examined the longitudinal development of individual level affect regarding the intervention group and the control group. In both test the same questionnaire was used as in research task 2 and 3. We used the examinees' post test drawings of their mathematics classes to analyze the social level of affect. We also categorized the post-test drawings by considering whether the pupils in the drawing were pictured to be activated or de-activated using Pekrun's (2006) division of activating/de-activating emotions. The idea is that emotion can be positive, but de-activating (e.g. satisfaction); even being positive the emotion does not necessarily promote learning process. On the other hand, emotion can be negative but activating (e.g. anger); even being negative the emotion can motivate a pupil to improve learning.

There was a statistically significant difference between the pre-test and post-test regarding all the pupils, the intervention group, and the control group. The results indicate that there is a remarkable decline in pupils' affect regarding mathematics from the beginning of the $3^{\text {rd }}$ to the end of the 5 th grade in both the intervention group and control group. When testing the difference between the control group and the intervention group in the post-test separately to genders, a statistically significant difference was found regarding girls' development. This means that the girls had benefitted from the intervention, but not boys.

Regarding the social level of mathematics related affect, there was a statistically significant difference between the two groups in the post-test. The distribution of the control group in the post-test declined clearly compared to the situation in the pre-test, indicating that on social level the intervention made a positive impact. However, in both measurements there were over $10 \%$ of negative drawings, so even after the intervention the proportion of pupils experiencing their mathematics classes negative was noticeable. Only part of the drawings included anything activating or deactivating: this happened in 72 of 119 intervention pupils' drawings (63.0 $\%$ ), and in 77 of 138 control pupils' drawings (55.8\%). In the rest of the drawings nothing referring to being activated or de-activated was present.

We analyzed the activation expressed in the drawings and found seven categories of activation/de-activation: Cognitive (e.g. how to calculate), Cognitive and social (e.g. offering a helping hand), Just social (e.g. 


\section{Laura Tuohilampi-Affect and Significance}

listening to music together), Emotional: boredom (e.g. pupils saying they were bored), Emotional: enjoying/inspiring (e.g. expectations to learn new things), Emotional: mixed (e.g. both boredom and inspiration) and Other. (e.g. envy or envisioning). The drawings that were activating and positive covered more than half of the intervention group drawings $(54.3 \%)$, but less than fifth of the control group drawings $(16.9 \%)$. The drawings that were de-activating and negative covered almost third $(27,8 \%)$ of the intervention group drawings, but more than two thirds $(70,1 \%)$ of the control group drawings. There was a statistically significant difference between the two groups regarding the distributions in the categories.

\section{Discussion of the Results}

\section{Research Task 1}

As a confirmation to previous studies, we found out that Finnish students' mathematics related affect decrease rather dramatically during comprehensive school years. More specifically, enjoyment of mathematics was most likely to decrease during primary school years (between $3^{\text {rd }}$ grade and $6^{\text {th }}$ grade), whereas self-efficacy was most likely to decrease during lower secondary school years (between $6^{\text {th }}$ grade and $9^{\text {th }}$ grade). We could also identify clear gender differences: the decrease was more dramatic among girls than it was among boys. It is possible that the decrease of selfefficacy can be connected to the move from primary school to lower secondary school. The teaching is from there on given by subject teachers, and the change might be too challenging for many students. The content of mathematics becomes more abstract, and the students start to notice that some classmates are able to reach the level of abstract thinking easily.

\section{Research Task 2}

We investigated the validity and reliability of an imposed etic approach in measuring affective aspects of mathematics in different cultures. The questionnaire was considered to be valid for Finnish students, allowing to identify the factors of their affective structure, but less valid for Chilean pupils, as for them the affective factors were not clearly identifiable, nor distinguishable with that instrument. Clarke (2013) argues that the 
researcher has to make a validity-comparability compromise: to emphasize either of the two. If looking for comparability, one could suggest that in international comparisons only the global components should be measured. According to our study, it is not obvious what components would be the universal ones. For example, in a model of Hannula $(2011$; 2012) emotions are distinguished from cognitive and motivational components of affect. Still, in our results the emotional component was connected with cognitive component among Chilean pupils, whereas among Finnish pupils' structure emotional and cognitive components distinguished, and instead the emotional and motivational components were connected. Our results suggest that the structures can merge differently in different cultures. Emphasizing comparability by measuring the universal factors becomes problematic if we acknowledge that the affective structures can be culturally dependent. In Clarke's (2013) words, the dilemma of inclusive vs. distinctive, rephrased as the premise of universalism regarding the examined components is present in the affect domain.

\section{Research Task 3}

In our results, the examined pupils showed mainly positive affect through the questionnaire and through the drawings. Also, the children were mostly positive about their affective learning climate. These results are in line with their developmental stage (Harter, 1999). They are young enough to see their perceptions mainly positive, but they increasingly make social comparisons in order to justify their self-construct. Though the distributions were mainly positive regarding the both levels of the affect, we found incongruence between the levels, indicating a possible independence between the affective levels. Even more, we saw the disparity between the cultural levels, as the disparity was not similar with respect to both countries. In Finland, most pupils expressed the individual level of affect very positive, but the interindividual level of affect clearly less positive. In Chile, the situation was opposite. Markus and Kitayama (1991) have argued that if the culture is individual, then individual level phenomena become very significant, structured and well identifiable, while in collective cultures the interindividual phenomena become more significant, more structured and more easily identified. In our results, the affect was more positive on individual level for Finnish pupils, who were considered to 
represent individual culture. For Chilean pupils, who were considered to represent collectivist culture, the interindividual level of affect appeared more positive. Such a cultural variation in valuing different affective levels suggest that we should use methods that cover more than one affective level in cross-cultural comparisons. Also, this cultural ontological variation can make the interpretations of cross-cultural results invalid; a challenge that can be connected with one of Clarke's (2013) dilemmas, evaluative criteria.

We used thematic analysis for selected drawings, revealing altogether six categories of ambivalence existent in mathematics classrooms. These categories were not universal between the countries. We saw that the reasons for ambivalence across the classes were more uniform in Finland than in Chile, as all the categories of ambivalence were present in almost all the Finnish classes. Regarding Chile, there were classes were the reasons for ambivalence varied across the classes, and in total there were more categories in Chilean drawings. There was bigger amount of categories in Chile and the more variation between the classes as an indicator to what has been presented by Markus and Kitayama (1991). They argue that individuals in collectivist cultures focus more on their social environment than do independent individuals. Thus the ones that live in more collectivist cultures might be able to notice different type of variation in their surroundings. Even though there were greater variations between the classes in Chile than in Finland, the classes themselves were more uniform in Chile in terms of the reasons of ambivalence. Unlike in Finland, there was no class in Chile were all the categories would have been present.

\section{Research Task 4}

The individual level as a whole turned from positive to negative from the beginning of $3^{\text {rd }}$ grade to the end of $5^{\text {th }}$ grade. This happened both among pupils that participated the intervention and the pupils that were studying in the control group classes. Even though the intervention could not prevent this detrimental development on the individual affective level regarding an average pupil, the results show a small-scale impact among girls. For the girls that participated the intervention the development of self-confidence and enjoyment of mathematics was less negative than it was on average.

This was an important result, bearing in mind that girls in particular suffer poor and unrealistic mathematical self-confidence worldwide 
(Syzmanowics \& Furham, 2011). On the other hand they estimate their verbal intelligence higher than males (ibid.). Because of that, girls may find it helpful to work in co-operation with others: Hannula, Kupari, Pehkonen, Räsänen \& Soro (2004) have argued that collaborative atmosphere and learning methods connect with increasing self-confidence and mathematical performance especially regarding girls. Thus, the benefit the intervention gave for girls might have come through the increase of collaboration. The intervention prevented social level of affect to develop detrimentally. Regarding the control group there was a clear decline. In the fifth study, we also elaborated the activation and de-activation illustrated in the drawings. Based on that analysis, we saw that 1) almost three fifth of all the 5th grade drawings did not relate to any kind of activation, neither to de-activation; 2) the number of the drawings expressing clearly positive activation was minimal in both groups; 3 ) the intervention group drawings included clearly more positive activation; and 4) the proportion of the emotionally boring mathematics classes was alarming, especially within the control group pupils.

Similar to findings of Nett, Goetz, \& Hall (2011), majority of the drawings indicated emotionally flat classrooms. We argued that the drawings suggest Finnish mathematics classes to be very non-activating or de-activating. Pupils very seldom expressed their mathematics classes emotionally positive or inspiring, so if there was activation, it was more likely related to cognitive actions than emotions.

\section{Implications}

We identified several cultural aspects that need to be addressed in crosscultural comparisons regarding mathematics. Based on Clarke's (2013) dilemmas, we confirmed the premise of universalism regarding the examined components, the premise of universalism within the components' significances, the premise of congruence between languages and conceptions and the premise of components' coverage among the phenomena to be problematic in the mathematics related affect domain. In order to acknowledge the culturally varying evaluation of different affective levels, we should use methods that cover more than one affective level in cross-cultural comparisons. Second, when aiming to focus on the most global affective components or factors only, one has to keep in mind that 
even the simplest measurements might relate to ontological differences. Third, the interpretations should be done using derived-etic approach; at least the interpretations need to be discussed in a dialogue between researches from inside and outside the culture.

The categories of ambivalence that were found show that during mathematics lessons pupils participate in other pupils' cognitive processes, behavioral habits, physically appearing emotions, and emotions expressed by facial expressions. It is possible that some affective phenomena pupils participate in their mathematics classes might have a specifically strong impact on self-construction. Future studies should go deeper in finding out the possible "cornerstone" experiences, envisioned just recently by Hannula (2015).

We noticed that individual and interindividual level of affect is not always coherent. In Finland the more meaningful level is better: there is intrinsic harmony and discrepancies emerge in the less significant level. Also in Chile the more meaningful level is better: there is harmony with others and the discrepancies stay in the less significant level. In future studies, the significance of different affective levels should be acknowledged, so that the ones that are most developed would not become omitted. Further, we saw that mathematics related affective on social level can be impacted by an activating intervention. The same intervention could make only moderate impact on pupils' individual level affect. Such results confirm that by examining more than just one level of affect a wider picture of mathematics related affect might be achieved.

The studies show that students' mathematics-related affect develop unnecessarily negative. Even though students' affect might not harm their performance, the negative affective bond with mathematics may result in students giving up mathematics. The centrality of beliefs makes negative development of mathematics-related affect something that counts. It is about experiencing mathematics in such a way that either makes or does not make the emotional bond connected with mathematics easy to carry. If the bond gets too negative, it may become central to the student to give up such a negative bond, and thus leave mathematics behind. In such a case, the achieved performance level becomes irrelevant for the students, and the resources put to educating children in mathematics gets wasted.

Based on our results of our studies, it is suggested to give more emphasis on students' control over their learning, to allow students to 
engage social interaction and to increase students' possibilities to work with open-ended problems in mathematics. However, all these recommendations have been given over years by several other researchers as well. Have there not been enough implications of such recommendations? Back in McLeod's (1992) days, he argued that the beliefs students generate reflect their experiences of the typical classroom situations where they encounter mathematics. As we still encounter same problems, we should remember McLeod's (1992, p. 579) words: there is nothing wrong with the students' mechanism for developing beliefs about mathematics; what needs to be changed is curriculum, and beyond that, the culture that encourages such beliefs.

\section{References}

Andrews, P. \& Diego-Mantecón, J. (2014). Instrument adaptation in crosscultural studies of students' mathematics-related beliefs: Learning from healthcare research. Compare: A Journal of Comparative and International Education. Helsinki: Finaldn. doi:10.1080/ 03057925.2014 .884346

Berry, J. W. (1989). Imposed etics-emics-derived etics: The operationalization of a compelling idea. International Journal of Psychology, 5, 165-171. doi: 10.1080/00207598908247841

Bronfenbrenner, U. (1993). The ecology of cognitive development: Research models and fugitive findings. In. R. H. Wozniak \& K. W. Fischer (Eds.), Development in context: Acting and thinking in specific environments. The Jean Piaget symposium series (pp. 3-44). Hillsdale, NJ, England: Lawrence Erlbaum Associates.

Chamberlin, S. A. (2010). A review of instruments created to assess affect in mathematics. Journal of Mathematics Education, 3(1), 167-182.

Chapman, O. (2002). Beliefs structure and inservice high school mathematics teacher growth. In G. C. Leder, E. Pehkonen, \& G. Törner (Eds.), Beliefs: A Hidden Variable in Mathematics education? (pp. 177-193). Kluwer Academic Publishers, Netherlands.

Clarke, D. (2013). The validity-comparability compromise in crosscultural studies in mathematics education. In B. Ubuz, Ç. Haser \& M. A. Mariotti (Eds.), Proceedings of the Eighth Congress of the European 
Society for Research in Mathematics Education (pp. 1855-1864). Antalya, Turkey: ERME.

Clarke, D. (2015). Faith, hope and charity: Theoretical lenses on affect. In B. Pepin, B. Roesken-Winter (Eds.), From beliefs to dynamic affect systems in mathematics education (pp. 119-134). Switzerland: Springer.

Di Martino, P., \& Zan, R. (2015). The construct of attitude in mathematics education. In B. Pepin, B. Roesken-Winter (Eds.), From beliefs to dynamic affect systems in mathematics education (pp. 269-277). Switzerland: Springer.

Evans, J. (2006). Affect and Emotion in Mathematical Thinking. In J. Maasz, \& W. Schloeglmann (Eds.), New mathematics education and practice (pp. 233-255). Sense Publishers: Netherlands.

Evans, I. M., Harvey, S. T., Bucley, L. \& Yan, E. (2009). Differentiating classroom climate concepts: academic, management, and emotional environments. New Zealand Journal of Social Sciences, 4(2), 131146. doi: 10.1080/1177083X.2009.9522449

Fennema, E., \& Sherman, J. A. (1976). Fennema-Sherman mathematics attitudes scales. JSAS Catalog of Selected Documents in Psychology, 6, 31 (Ms. No. 1225).

Green, T. F. (1971). The Activities of Teaching. New York: McGraw-Hill. Hannula, M. S. (2011). The structure and dynamics of affect in mathematical thinking and learning. In M. Pytlak, T. Rowland, \& E. Swoboda (Eds.), Proceedings of the Seventh Congress of the European Society for Research in Mathematics Education (pp. 3460). Rzeszów, Poland: ERME.

Hannula, M. S. (2012). Exploring new dimensions of mathematics-related affect: embodied and social theories. Research in Mathematics Education 14(2), 137-161. doi: 10.1080/14794802.2012.694281

Hannula, M. S. (2015). The relevance of affective systems and social factors: a commentary. In B. Pepin, B. Roesken-Winter (Eds.), From beliefs to dynamic affect systems in mathematics education. (pp. 269277). Switzerland: Springer.

Hannula, M. S. \& Laakso, J. (2011). The structure of mathematics related beliefs, attitudes and motivation among Finnish grade 4 and grade 8 students. In B. Ubuz (Ed.), Proceedings of the 35th conference of the 
international group for the psychology of mathematics education, Vol. 3, (pp. 9-16). Ankara, Turkey: PME.

Hannula, M. S., Kupari, P., Pehkonen, L., Räsänen, P., \& Soro, R. (2004). Matematiikka ja sukupuoli [Mathematics and gender]. In P. Räsänen, P. Kupari, T. Ahonen, \& P. Malinen (Eds.), Matematiikkanäkökulmia opettamiseen ja oppimiseen [Mathematics - percpectives to teaching and learning]. Jyväskylä, Finland: The Niilo Mäki Institute.

Hannula, M.S., Op 't Eynde, P., Schlöglmann, W \& Wedege, T. (2007). Affect and mathematical thinking. In D. Pitta - Pantazi \& G. Philippou (Eds.) European Research in Mathematics Education V, Proceedings of the Fifth Congress of the European Society for Research in Mathematics Education, Larnaca, Cyprus 22 - 26 February 2007, pp. 202 - 208. Department of Education: University of Cyprus.

Harter, S. (1999). The Construction of the Self. A Developmental Perspective. New York, NY: The Guildford Press.

Hirvonen, K. (2012). Onko Laskutaito Laskussa? Matematiikan Oppimistulokset Peruskoulun Päättövaiheessa 2011. [Are Calculating Skills Decreasing? Mathematics Learning Outcome at the End of the Comprehensive School at 2011.] Helsinki: The National Board of Education.

Hofstede, G. \& Hofstede, G. J. (2005). Cultures and Organizations. Software of the Mind. New York, NY: McGraw-Hill.

Lee, J. (2009). Universals and specifics of math self-concept, math selfefficacy, and math anxiety across 41 PISA 2003 participating countries. Learning and Individual Differences 19, 355-365.

Lerman, S. (2000). The social turn in mathematics education research. In J. Boaler (ed.), Multiple Perspectives on Mathematics Teaching and Learning (pp. 19-44). Westport, CT.: Ablex.

Ma, X., \& Kishor, N. (1997). Assessing the relationship between attitude toward mathematics and achievement in mathematics: A metaanalysis. Journal for research in mathematics education, 26-47.

Markus, H. \& Kitayama, S. (1991). Culture and the self: implications for cognition, emotion and motivation. Psychological Review, 98(2), 224-253. 
McLeod, D. B. (1992). Research on affect in mathematics education: A reconceptualization. In D. A. Grows (Ed.), Handbook of research on mathematics learning and teaching (pp. 575-596). New York, NY: Macmillan.

Midgley, C., Kaplan, A., Middleton, M., Maehr, M. L., Urdan, T., Anderman, L. H., ... \& Roeser, R. (1998). The development and validation of scales assessing students' achievement goal orientations. Contemporary Educational Psychology, 23(2), 113-131. doi: 10.1006/ceps.1998.0965

Midgley, C., Maehr, M. L., Hruda, L. Z., Anderman, E., Anderman, L. Freeman, K. E., ... Urdan, T. (2000). Manual of the patterns of adaptive learning scales. University of Michigan. Retrieved from http://www.umich.edu/ pals/PALS 2000_V13Word97.pdf

Nett, U. E., Goetz, T., \& Hall, N. C. (2011). Coping with boredom in school: An experience sampling perspective. Contemporary Educational Psychology, 36(1), 49-59. doi:

10.1016/j.cedpsych.2010.10.003

Op' t Eynde, P., de Corte, E., \& Verschaffel, L. (2002). Framing students' mathematics-related beliefs. In G. C. Leder, E. Pehkonen, \& G. Törner (Eds.), Beliefs: A Hidden Variable in Mathematics education? (pp. 13-37). Netherlands: Kluwer Academic Publishers.

Pehkonen, E. (1994). On differences in pupils' conceptions about mathematics teaching. The Mathematics Educator, 5(1), 3-10.

Pekrun, R. (2006). The control-value theory of achievement emotions: Assumptions, corollaries, and implications for educational research and practice. Educational Psychology Review, 18, 315-341. doi: 10.1007/s10648-006-9029-9

Reyes, M. R., Brackett, M. A., Rivers, S. E., White, M., \& Salovey, P. (2012). Classroom emotional climate, student engagement, and academic achievement. Journal of Educational Psychology, 104, 700-712. doi: 10.1037/a0027268

Sjøberg, S., \& Schreiner, C. (2010). The ROSE project. Overview and key findings. Retrieved from:

http://roseproject.no/network/countries/norway/eng/nor-SjobergSchreiner-overview-2010.pdf

Syzmanowicz, A. \& Furnham, A. (2011). Gender differences in selfestimates of general, mathematical, spatial and verbal intelligence: 
Four meta analyses. Learning and Individual Differences 21(5), 493504. doi: 10.1080/00224545.2012.754397

Thapa, A., Cohen, J., Guffey S., and Higgins-D' Alessandro, A. (2013). A

Review of School Climate Research. Review of Educational

Research 83(3), 357-385. doi:

http://dx.doi.org/10.3102/0034654313483907

Turner, J. C., Midgley, C. Meyer, D. K., Gheen, M., Anderman, E. M., Kang, Y., \& Patrick, H. (2002). The classroom environment and students' reports of avoidance strategies in mathematics: A multimethod study. Journal of Educational Psychology, 94(1), 88106. doi: 10.1037//0022-0663.94.1.88

Wong, N. (2008). Confucian heritage culture learner's phenomenon: from "exploring the middle zone" to "constructing a bridge". ZDMInternational Journal of. Mathematics Education, 40, 973-981. doi: http://dx.doi.org/10.1007/s11858-008-0140-x

Yackel, E., \& Cobb, P. (1996). Sociomathematical norms, argumentation, and autonomy in mathematics. Journal for research in mathematics education, 458-477.

Laura Tuohilampi is doctoral student, in the University of Helsinki, Finland.

Contact Address: Direct correspondence concerning this article, should be addressed to the author. Postal address: Siltavuorenpenger, 5, 00014 Helsinki. Email: laura.tuohilampi@helsinki.fi 